\title{
ARQUITETURA DA INFORMAÇÃO NO CONTEXTO DE GÊNERO: Uma análise do site da Secretaria Nacional de Políticas para Mulheres
}

\author{
Gracione Batista Carneiro Almeida \\ Mestranda em Biblioteconomia \\ Programa de Pós-Graduação em Biblioteconomia \\ Universidade Federal do Cariri \\ bgracione@yahoo.com.br
}

Ana Karolyne Nogueira de Sousa Mestranda em Biblioteconomia Programa de Pós-Graduação em Biblioteconomia Universidade Federal do Cariri anikarolyne@gmail.com

Henry Poncio Cruz Oliveira Doutor em Ciência da Informação Professor do Programa de Pós-Graduação em Ciência da Informação

\section{Resumo}

Esta pesquisa tem como objetivo a análise da arquitetura da informação da página da Internet da Secretaria Nacional de Políticas para Mulheres, com intuito de diagnosticar possíveis problemas na estrutura arquitetural do site e sugerir modificações no sentido de corrigir inconsistências na arquitetura da informação. A presente pesquisa se apresenta como bibliográfica e exploratória tendo como base os pressupostos teóricos da arquitetura da informação em um contexto social vinculada ao debate sobre as questões de gênero. Metodologicamente, utiliza a Netnografia como caminho para coleta e análise dos dados. As análises apontam, entre outros resultados, necessidade de ajustes na arquitetura do site da Secretaria Nacional de Políticas para Mulheres, na padronização das fontes tipográficas utilizadas na página, redefinição taxonômica nos tópicos do sistema de navegação, para melhoramento da recuperação das informações por meio do sistema de busca.

Palavras-chave

Arquitetura da informação. Gênero. Secretaria Nacional de Políticas para mulheres.

\section{INTRODUÇÃO}

A sociedade atual é constituída de diversas transformações que possibilitaram demonstrar e refletir sobre os seus insumos e ideários. Neste contexto, a informação e o conhecimento são tidos como os principais produtos de aspiração, negociação, desejos e realizações no âmbito micro e macro da sociedade, tendo sido impulsionados pelas Tecnologias de Informação e Comunicação (TIC). Dessa forma, novos ambientes têm sido estruturados para melhor corresponder aos anseios e necessidades informacionais no contexto da Internet, potencializando a construção de ambientes digitais devotados à expansão e disseminação da informação.

De acordo com Cardoso (2006), a Internet assumiu a função de ferramenta de construção de projetos individuais desenvolvidos a partir de diferentes dimensões, sendo constituída por uma apropriação flexível, interativa, dotada de ubiquidade, global, acessível, que não depende dos poderes passados ou existentes. Nesta perspectiva, a Internet permitiu um aumento exponencial de criação de informações, devido às múltiplas ferramentas que possibilitaram ao indivíduo a produção e o consumo em mídias digitais, redes sociais, sites, bases de dados, 
entre outros. Apesar disso, há problemas que findam por impossibilitar a localização, o uso e o acesso das informações, causando transtornos e atrasos para os usuários que as necessitam. Por isso, se faz necessário um estudo descritivo e analítico da Arquitetura da Informação (AI) em diversos ambientes de informação digital, pois ela possibilita diagnosticar e minimizar os erros e problemas, ou mesmo prevenir possíveis inconsistências e ambiguidades nos ambientes digitais.

As mídias as quais nos referimos neste estudo são pensadas e elaboradas com o propósito de disseminar informação e possibilitar uma interação dialógica entre sujeitos de sua audiência, sendo uma importante ferramenta de construção do conhecimento. Alguns sites trazem temáticas direcionadas para um determinado público e possuem forte relevância social, como o site da Secretaria Nacional de Políticas para Mulheres, que expõe a questão do gênero e da luta das mulheres pela conquista do direito de igualdade. Neste sentido, este trabalho se fundamenta a partir do seguinte questionamento: como a AI pode contribuir com o site da Secretaria Nacional de Políticas para Mulheres? Para tanto, este trabalho tem como objetivo avaliar a AI da referida página da Internet, com base nos autores Rosenfeld, Morville e Arango (2015).

Quanto aos procedimentos metodológicos, esta pesquisa se apresenta como bibliográfica e exploratória, pautando-se em publicações acerca do tema proposto, bem como no uso de fontes de informação para a construção do referencial teórico e para análise e resultados da pesquisa. Compõe-se também por ser uma pesquisa descritiva e transversal, devido ao aprofundamento e detalhamento do objeto de estudo e suas características. Ressalta-se que também foi empregada a Netnografia como uma metodologia adequada para analisar os dados.

Inicialmente a pesquisa apresenta uma discussão relacionada à questão de gênero, pois a temática geral fala sobre a Secretaria Nacional de Políticas para Mulheres, sendo assim faz-se necessária esta discussão. Em seguida, realiza-se uma reflexão sobre a arquitetura da informação em websites, procurando compreender seus conceitos e aplicálos no contexto do objeto de pesquisa. A análise dos resultados permitiu identificar os erros e acertos no site no âmbito da arquitetura da informação.

\section{ARQUITETURA DA INFORMAÇÃO}

As informações que são veiculadas nos sites devem ser estruturadas de forma clara e organizada em função de seus usuários, para que não haja problemas ou ruído na recepção ou no acesso às informações. Nesses ambientes digitais, o tratamento e a organização dos conteúdos são construídos por diversos colaboradores que, por vezes, não produzem ambientes de fácil uso para todos os públicos (OLIVEIRA, 2014). Nesta perspectiva, a AI atua com intuito de projetar, analisar e avaliar os ambientes de informação digital no sentido de amenizar os problemas de organização, de apresentação e de acesso desses elementos informacionais, com vistas a facilitar a navegação nos ambientes de informação digital. Oliveira (2014) e Oliveira, Vidotti e Bentes Pinto (2015) alegam que a AI é usada para o melhoramento do acesso e do uso da informação em ambientes analógicos e/ou digitais desde a década de 1980.

A AI é um campo científico que surgiu em meados de 1970, fortemente divulgado pelo arquiteto e designer gráfico Richard Saul Wurman, tendo como foco a racionalização de estruturas informacionais ou mapas de informação que permitissem aos usuários encontrar seus caminhos para a construção de conhecimentos em ambientes informacionais (WURMAN, 1996). Desde então, tornou-se um campo de estudo bastante relevante, com fortes influências e relações com a Biblioteconomia e a Ciência da Informação. Esta visão relacional é defendida por importantes e influentes autores da área, como Louis Rosenfeld e Peter Morville, formados em Biblioteconomia e Ciência da Informação, cujos estudos e pesquisas resultaram em um livro de referência para o campo, "Information Architecture for the World Wide Web", publicado em 1998, obtendo outras 
edições publicadas nos anos de 2002 e 2006, e, mais recentemente, em 2015, a obra foi republicada com a participação de Jorge Arango e o título "Information Architecture: for the web and beyond".

Rosenfeld, Morville (1998; 2002; 2006) definem a AI como uma arte e disciplina emergente, como uma comunidade de práticas focada em trazer princípios do design e da arquitetura para os ambientes digitais, no intento de organizar informações para auxiliar os indivíduos em suas necessidades informacionais. Complementando, Albuquerque e Lima Marques (2011) referem-se a um esforço sistemático de identificação de padrões e criação de metodologias para a definição de espaços de informação, tendo como propósito a representação e manipulação de informações e a criação de relacionamentos entre entidades linguísticas. Nesta linha de entendimento, atem-se sobre as formas de representação e organização das informações, com o intento de melhor apresentá-las aos usuários.

De acordo com Santos (2001), a AI pode ser caracterizada como uma forma de aprimorar a usabilidade de um sistema por meio do desenvolvimento de uma estrutura de informação, que possibilite ao usuário atingir suas metas de interação durante o processo de busca de informação em um ambiente de informação digital. Isso corrobora com o pensamento de Silva e Dias (2008, p. 4), que afirmam:

Atender às necessidades de informação dos usuários é o grande objetivo da Arquitetura da Informação na web, através da organização da informação em websites, de forma que os usuários consigam encontrá-las e alcancem seus objetivos.

Ou seja, os autores aqui articulados enfatizam que a AI possibilita a maximização da usabilidade nos ambientes de informação digital, de modo a suprir adequadamente as necessidades informacionais dos usuários por meio de uma navegação intuitiva e forte interação entre usuário e sistema.

Rosenfeld, Morville e Arango (2015) aduzem que a AI pode ser descrita como: a) desenho estrutural de ambientes de informação compartilhados;

b) síntese de sistemas de organização, rotulagem, busca e navegação dentro de ecologias digitais, físicas e cross-channel;

c) a arte e a ciência de dar forma à produtos informacionais e experiências com suporte à usabilidade, encontrabilidade e compreensão.

Desse modo, o universo de análise da AI perpassa todos os elementos que possam formar os ambientes informacionais digitais, desenvolvendo uma melhor forma de comunicação e interação com os seus usuários.

Para tanto, a AI contempla aspectos da subjetividade por estar preocupada com as percepções e compreensões dos sujeitos/usuários, bem como aspectos da objetividade visto que se preocupa em mapear, definir e gerenciar o armazenamento e o uso de estruturas de dados e informações que se materializam por meio de experiências tecnológicas.

A partir desse entendimento, Bentes Pinto, Tabosa e Vidotti (2011) asseveram que a $\mathrm{AI}$, tanto trata da arquitetura do espaço de pedra e cal, quanto da estrutura física do ambiente em que as informações são armazenadas e geridas, como também contemplam os conteúdos a serem alocados nesses espaços. Para tanto, AI tornou um campo relevante devido à grande carga informacional gerada na Internet, contribuindo para a racionalização, a organização das estruturas e o funcionamento dos ambientes de informação digital, e o melhor uso/interação.

\section{GÊNERO E POLÍTICAS PARA AS MULHERES}

As mulheres têm construído espaços de luta nos diversos seguimentos da sociedade, ampliando espaços de atuação no mercado de trabalho e ressignificando as representações sociais que impactam na vivência da sexualidade, na concepção de família, entre outros campos da vida social.

A propositura de políticas públicas com foco nas mulheres, ou seja, políticas de 
"gênero" tem o potencial de solidificar e dar sentido às mudanças que se pretende, sobretudo, aquelas que fortalecem a condição emancipatória e a dimensão de autonomia das mulheres para que as desigualdades de gênero sejam combatidas no contexto do conjunto das desigualdades (BRASIL, 2017).

As histórias das mulheres são construídas no interior de uma sociedade marcadamente patriarcal, em que o homem é representado como um gênero superior, que detém força física e poder sobre a mulher, no mercado de trabalho, na casa, nas vivências da sexualidade. Neste cenário de representações, as mulheres deveriam ocupar os papeis de mãe, esposa e doméstica. Porém, rupturas históricas com este paradigma têm colocado as mulheres nos mais diversos postos de trabalho, nas universidades e centros de pesquisa, na vida política e econômica da sociedade, entre outros lugares. O cenário acima delineado induz a elaboração, a articulação e a efetivação de políticas públicas para as mulheres que

[...] somente será realizada se houver a institucionalização, nos estados e nos municípios, de instâncias governamentais - secretarias, coordenadorias de políticas para as mulheres capazes de realizar essas políticas, visando diminuir as desigualdades entre homens e mulheres. (BRASIL, 2017, p. 9).

Para Almeida (2010), o patriarcado é empregado inicialmente para designar um regime de organização familiar, em que o pai, como chefe, tinha o poder irrestrito sobre os membros da família. Da mesma forma que foi adotado para nomear um sistema de relações em que os donos de grandes extensões de terras, coronéis e latifundiários, tinham um domínio sobre todas as pessoas que residiam em suas propriedades.

No período colonial, algumas mulheres começaram a lutar de forma contida pelos seus direitos, destacando a conquista pelo direito à educação. Somente a partir de 1934, as mulheres conquistaram o voto nas eleições, bem como fazendo parte das decisões políticas do país, suscitando as questões de gênero (ALMEIDA, 2010).
Nesse contexto, entende-se o gênero como uma construção social que se relaciona com a questão biológica que define o sexo, todavia, o significado de gênero é mais amplo e significativo. Para Torrão Filho (2005, p. 135),

O gênero é uma primeira maneira de dar significado às relações de poder. Seria melhor dizer: o gênero é um primeiro campo no seio do qual, ou por meio do qual, o poder é articulado.

Neste sentido, este autor define gênero como significado de poder.

Enquanto construção social, o gênero pode ter relação com a construção de identidades. Neste campo de identidades, considera-se:

\footnotetext{
Gênero com o qual uma pessoa se identifica, que pode ou não concordar com o gênero que lhe foi atribuído quando de seu nascimento. Diferente da sexualidade da pessoa. Identidade de gênero e orientação sexual são dimensões diferentes e que não se confundem. (JESUS, 2012, p. 14).
}

Almeida (2010) compreende o gênero como as relações sociais que se dão entre homens e mulheres que podem ser desiguais, igualitárias ou contraditórias. Porém, na sociedade patriarcal, essas relações são completamente desiguais e a questão do gênero se sobressai como de um sujeito sobre o outro, como um exercício de poder desigual de homens sobre mulheres.

Saffioti (2004) alude que no interior dessas relações se interpõem a construção do masculino e do feminino, padronizada na funcionalidade dos papéis sociais que moldam atitudes diferenciadas e desiguais entre homens e mulheres. Essas padronizações começam desde a infância, em que é determinado o que faz parte do mundo masculino e do feminino, como escolher a cor rosa para meninas e azul para meninos, ou então, a menina brinca de boneca e menino de carrinho. Esse sistema provoca uma dualidade de gênero entre homens e mulheres, colocando-os como unidades opostas. Essas diferenças também eram refletidas na litera- 
tura e na arte, em que as mulheres eram descritas e representadas como loucas, prostitutas ou somente mãe e esposa.

O conceito de gênero ganhou amplitude na década de 1990 em determinados espaços sociais, como nas universidades, ONGS, movimentos socias e entres outros. Tal conceito é fundante no contexto do movimento feminista, que constrói as lutas das mulheres pela igualdade social, econômica e política na sociedade (CARVALHO, 2011).

Vale ressaltar a importância do movimento feminista na história de luta por igualdade de direitos entre homens e mulheres. Este movimento social e político se fortaleceu no início do século XIX, com a conquista do direito ao voto para a mulher, a sua inserção no mercado de trabalho, a implantação de delegacias especializadas, entre outros. Para Teles (1999, p.10):

Em seu significado mais amplo, o feminismo é um movimento político. Questiona as relações de poder, a opressão e a exploração de grupos de pessoas sobre outras. Contrapõe-se radicalmente ao poder patriarcal. Propõe uma transformação social, econômica, política e ideologia da sociedade.

Diante disso, percebe-se a relevância do movimento feminista, não somente para as mulheres, mas para a sociedade como um todo, pois contribui de forma significativa em diversos setores da sociedade ao possibilitar novas formas de interação e relação entre os gêneros. Foi a partir das lutas individuais e coletivas, através de movimentos como o feminismo, que as mulheres puderam conquistar e ocupar mais espaço na política, no mercado de trabalho e na economia. Apesar de tudo isso, infelizmente, uma parcela significativa das mulheres ainda sofre com a violência, o preconceito e a discriminação.

\section{PROCEDIMENTOS METODOLÓ- GICOS}

A metodologia é por fundamento o caminho a ser traçado ou o processo para elaboração da pesquisa. De acordo com Minayo (1982), a pesquisa científica é uma bus- ca contínua com a finalidade de definir um processo permanente e essencialmente inacabado, que se estabelece por meio de uma atividade de aproximação com a realidade, combinando dados e informações com as teorias. Nesta perspectiva, este estudo pode ser considerado como uma pesquisa bibliográfica, tendo em vista que reuniu publicações acerca do tema proposto por meio de livros, artigos de periódicos científicos, dissertações e teses relacionadas à AI e às questões de Gênero. Desse modo, destacam-se como fontes principais da pesquisa, a saber: Portais de Periódicos Científicos Eletrônicos de Universidades, Portal de Periódicos da Capes, BRAPCI, BDTD e Repositórios Institucionais.

Trata-se de um estudo exploratório, descritivo e transversal, conduzido no site da Secretaria Nacional de Políticas para as $\mathrm{Mu}-$ lheres. As pesquisas descritivas são, juntamente com a exploratória, as que permitem realizar um aprofundamento detalhado da realidade entre os dados em relação ao objeto de estudo e suas características. Ressaltase que foi também empregada a Netnografia como uma metodologia adequada para o estudo do site em tela, tendo em vista ser bastante relacionado aos estudos da Internet. Corrêa e Rozados (2017) depreendem este método como uma ferramenta que permite o estudo de objetos, fenômenos e culturas que emergem constantemente no ciberespaço a partir do desenvolvimento e da apropriação social das TIC, tendo como foco as ações e interações dos indivíduos no ambiente digital nos elementos contextuais empregados para ampliar a compreensão do objeto.

Vale ressaltar que foi realizado o recolhimento dos dados no site, no período de 21 a 25 de agosto de 2017, tendo como ferramentas de navegação o Google Chrome, e a utilização do recurso de extensão o Nimbus Screenshot, que possibilitou a captura das telas e edição das imagens do site. Portanto, seguidos os métodos estabelecidos e os objetivos do trabalho segue a caracterização do objeto e análise dos dados do website da Secretaria Nacional de Políticas para as Mulheres. 


\subsection{Caracterização do objeto}

Convém mencionar a importância, no cenário brasileiro dos movimentos socias, as páginas da Internet, órgãos e secretarias que promovam os direitos das mulheres em combater qualquer forma de intolerância, discriminação e violência contra a mulher. Ressalta-se que a Secretaria Nacional de Políticas para Mulheres é um dos meios que divulga, auxilia e atua em todo o país com ações, programas e políticas para a eliminação das desigualdades de gênero. Assim, a secretaria tem como principal objetivo promover a igualdade entre homens e mulheres e combater todas as formas de preconceito e discriminação, lutando para a construção de um Brasil mais justo, igualitário e democrático, por meio da valorização da mulher e de sua inclusão no processo de desenvolvimento social, econômico, político e cultural do País (BRASIL, 2017).

A criação da Secretaria de Políticas para Mulheres está respaldada na Medida Provisória (MP) $n^{\circ} 726$, publicada no Diário Oficial da União no dia 12 de maio de 2016, que estabeleceu a nova estrutura organizacional da Presidência da República e dos Ministérios que compõem o Governo Federal, de modo que oficializou a extinção do Ministério das Mulheres, da Igualdade Racial, da Juventude e dos Direitos Humanos, que foi criado em 13 de outubro de 2015, pela MP 696, com a junção da Secretaria de Políticas de Promoção da Igualdade Racial (Seppir); Secretaria de Políticas para as $\mathrm{Mu}-$ lheres (SPM); Secretaria de Direitos Humanos (SDH) e Secretaria Nacional de Juven- tude (SNJ). Assim, foi extinto o Ministério das Mulheres, da Igualdade Racial, da Juventude e dos Direitos Humanos, mas permanece na condição de Secretaria Nacional de Políticas para as Mulheres, passando a ser vinculada ao Ministério da Justiça e Cidadania (BRASIL, 2017).

Do ponto de vista técnico, o site da Secretaria Nacional de Políticas para as $\mathrm{Mu}-$ lheres, disponível no endereço eletrônico http://www.spm.gov.br/, foi desenvolvido a partir do Plone que é um Content Management Service (CMS). O Plone é um projeto de código aberto distribuído em todo o mundo. Tem mais de 103.000 comitês e quase 900 colaboradores de código, representando cerca de 1.250.000 linhas de código. O projeto foi desenvolvido ativamente desde 2001, está disponível em mais de 40 idiomas e tem o melhor histórico de segurança de qualquer grande CMS (PLONE, 2018).

\section{ANÁLISE DOS DADOS}

Para realizar a análise dos dados utilizou-se a Netnografia, entendida como um ramo da Etnografia que estuda tecnologias e o comportamento de grupos sociais na Internet. Para Amaral et al. (2008) a Netnografia dá importância às práticas de consumo midiático, aos processos de sociabilidade e aos fenômenos comunicacionais que envolvem as representações do homem dentro de comunidades digitais. $\mathrm{Na}$ pesquisa ora apresentada, a Netnografia foi capaz de subsidiar de forma sistemática a avaliação dos sistemas de AI no site da Secretaria Nacional de Políticas para as Mulheres.

\begin{tabular}{|c|l|}
\hline \multicolumn{2}{|c|}{ Quadro 1 - Sistemas da arquitetura da informação } \\
\hline SISTEMAS & \multicolumn{1}{c|}{ DEFINIÇÃO } \\
\hline Organização & $\begin{array}{l}\text { Define as características compartilhadas de itens de conteúdo e influencia o } \\
\text { agrupamento lógico de tais itens, posto que uma estrutura de organização defi- } \\
\text { ne os tipos de relações entre os itens de conteúdo e dos grupos. }\end{array}$ \\
\hline Navegação & $\begin{array}{l}\text { Especifica as maneiras de navegar, de se mover pelo espaço informacional } \\
\text { digital através de uma teia hipertextual. }\end{array}$ \\
\hline Rotulagem & $\begin{array}{l}\text { Estabelece as formas de representação e de apresentação da informação, defi- } \\
\text { nindo signos para cada elemento informativo. }\end{array}$ \\
\hline Busca & $\begin{array}{l}\text { Auxilia na localização e no acesso rápido às informações armazenadas e apre- } \\
\text { sentadas no ambiente de informação. }\end{array}$ \\
\hline $\begin{array}{c}\text { Tesauros, vocabulários con- } \\
\text { trolados e metadados }\end{array}$ & $\begin{array}{l}\text { São elementos de representação que ajudam na navegação suplementar, ofere- } \\
\text { cendo recursos que permitem fazer cruzamento entre conteúdos por relações } \\
\text { diretas ou de dependência. }\end{array}$ \\
\hline Fonte: Extraído de Rosenfeld, Morville e Arango (2015)
\end{tabular}

Ci. Inf. Rev., Maceió, v. 5, n. 3, p. 30-42, set./dez. 2018 
Utilizou-se ainda a visão dos autores Rosenfeld, Morville e Arango (2015) para melhor compreensão desta análise, que afirmam que a AI de um ambiente de informação digital aglutina os sistemas de organização; de navegação; de rotulagem; de busca, e os elementos de representação: tesauros, vocabulários controlados e metadados. Esses sistemas são descritos com características e funções específicas, que possibilitam uma melhor navegação, uso e interação de todas as partes que compõem o ambiente digital. No Quadro 1, constam algumas definições dos sistemas que atuam de forma integrada.

Doravante, detalharemos os sistemas, apresentados no Quadro 1, no contexto do site da Secretaria Nacional de Políticas para Mulheres.

\subsection{Sistemas de organização}

Segundo Rosenfeld, Morville e Arango (2015), uma estrutura de organização define os tipos de relações entre os itens de conteúdo e dos grupos. No que tange aos tipos de esquemas de organização, são classificados por exatos e ambíguos. Os exatos podem constituir em alfabéticos, cronológicos e geográficos. Já os esquemas ambíguos podem ser vistos em uma estrutura de tópicos, tarefas, audiência, etc. Com isso, o site em tela apresenta as publicações categorizadas por ano, o que caracteriza uma estrutura exata de ordem cronológica. Contempla também, um esquema de organização ambíguo por tópicos, como pode ser visualizado na primeira dimensão da Figura 1.

Figura 1 - Estrutura de organização por tópicos e ordem cronológica

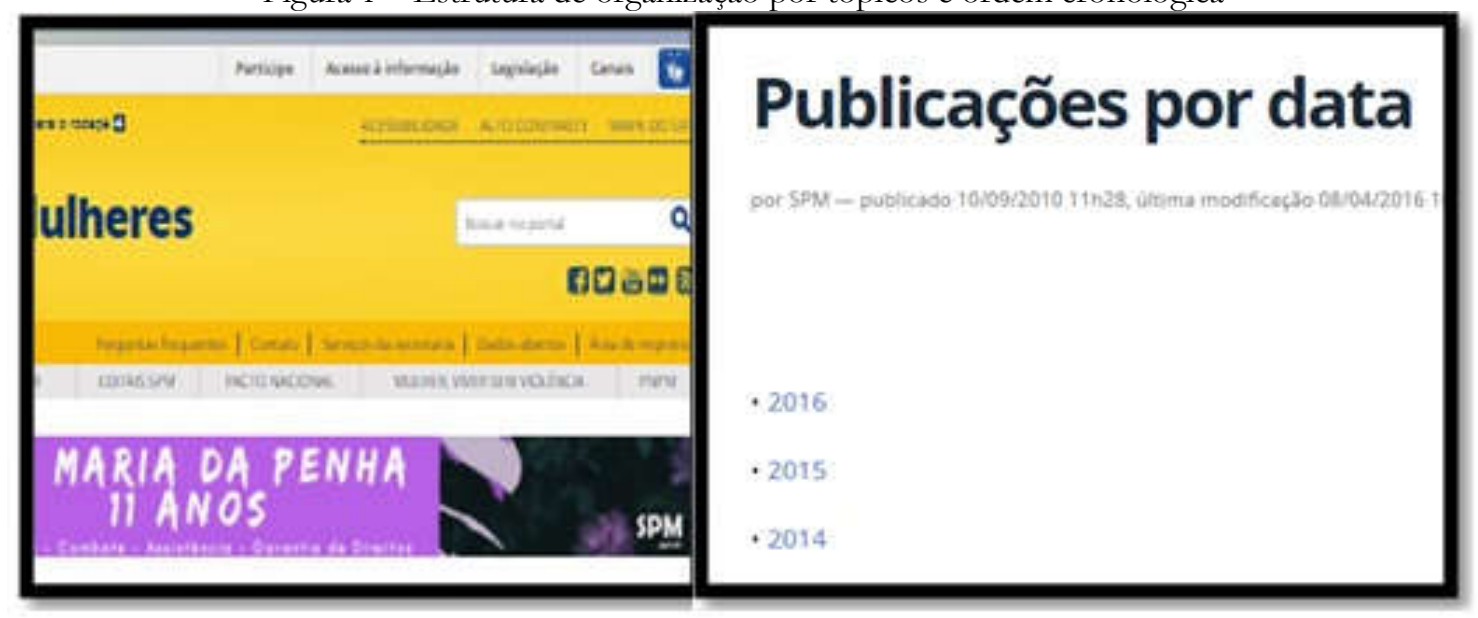

Fonte: Extraído de Brasil (2017).

Neste mesmo aspecto da organização das estruturas, os referidos autores mencionam a importância das hierarquias por fornecerem uma maneira simples e familiar de organizar as informações e para os processos da AI. Isto posto, esclarecem que pode haver dentro de uma estrutura hierárquica taxonomias estreitas e profundas, ou largas e rasas. Rosenfeld, Morville e Arango (2015) asseveram também que a profundidade se refere ao número de níveis em hierarquia e, se uma hierarquia é muito estreita e profunda, os usuários precisam clicar em um número excessivo de níveis para encontrar o que estão procurando. Para uma hierarquia larga e rasa, os usuários devem escolher entre várias categorias, em que terão muitas opções no menu principal.

Nesta perspectiva, o site em estudo possui uma estrutura hierárquica, tendo uma taxonomia caracterizada por larga e profunda. É também hipertextual e heterogênea, tendo em vista que oferece uma diversidade de formas de conteúdo, bem como organizados por tópicos dentro de uma escala de subordinação. 
Quanto à classificação social, oferecem interação em páginas do Facebook, Twitter, Youtube, Flicker, como também o recurso do RSS (Really Simple Syndication).

No que tange à estrutura de ordenamento do site, é vista como Top-Down, ou seja, projetada para em uma estrutura centrada 'de cima'. Dessa maneira, Rosenfeld, Morville e Arango (2015) elaboraram 10 questões que permitem melhor visualização dos componentes do site identificados na Figura 2. Com isso, segue as respostas das seguintes questões encontras no site do SNPM.

Figura 2 - Top-Down

- Onde estou? (1)

- Eu sei o que estou procurando? Como faço para buscá-10? (2)

- Como faço para percorrer este site? (3)

- 0 que é importante e exclusivo sobre essa organizaçăo? (4)

- 0 que há neste site? (5)

- O que esta acontecendo ai? (6)

- Como faço para me envolver com vários outros canais digitais populares? (7)

- Como posso contactar um humano? (8)

- Qual è o endereço deles? (9)

- Como posso acessar minha conta? (10)

Fonte: Adaptado de Brasil (2017).

A maioria dos requisitos foram encontrados no site, somente o requisito 10 , referente à possibilidade de haver um login de acesso aos usuários na página, não foi encontrado.

\subsection{Sistemas de navegação}

O sistema de navegação tem como objetivo auxiliar o usuário na navegação e fornecer o contexto e a flexibilidade necessários para que os usuários entendam onde estão e aonde podem ir. Rosenfeld, Morville e Arango (2015) alegam que os sistemas de navegação são compostos por vários elementos básicos ou subsistemas, classificando-os por tipos: global, local e contextual. Há também os sistemas suplementares que fornecem formas complementares de acesso ao conteúdo, que complementam os básicos, podendo garantir a usabilidade e a capacidade de busca dentro de grandes sistemas de informação. Assim, incluem os sistemaps, os índices e os guias. Dessa forma, segue a Figura 3 contemplando os elementos mencionados no site em análise.

Conforme mostra a Figura 3, o sistema de navegação global é a estrutura que permanecerá em todas as demais telas navegáveis no site, contemplando as ligações com Home Page, a função de busca e tópicos. A navegação contextual são links específicos de uma determinada página ou documento, apresentados nos conteúdos dos textos, geralmente de forma hipertextual. A navegação local, pode aparecer juntamente com a navegação global, de forma a complementar e permitir que o usuário possa explorar os conteúdos rapidamente. 
Figura 3 - Sistemas de navegação

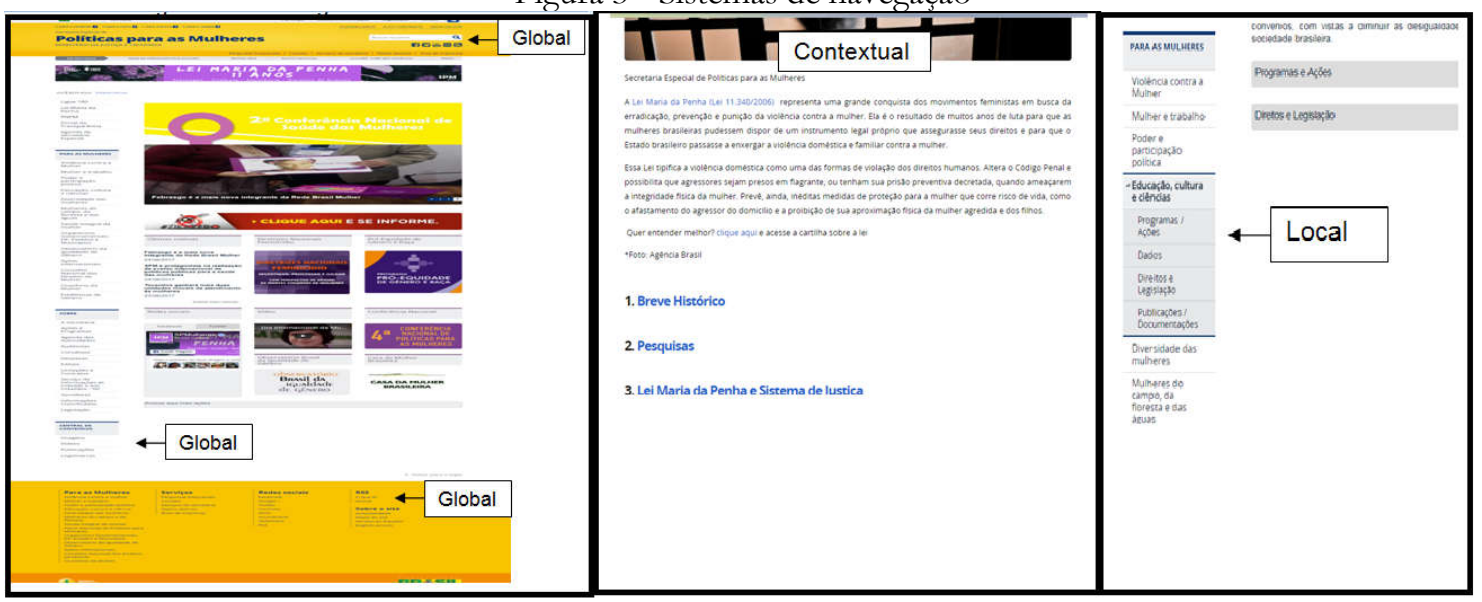

Fonte: Adaptado de Brasil (2017).

O site aqui estudado também apresenta navegação suplementar por meio do Sitemap, além de apresentar a navegação social oferecendo interação com as redes sociais, já mencionadas anteriormente. Bem como oferece o recurso breadcrumb, conhecido como 'migalhas de pão', que possibilita ao usuário visualizar e acompanhar todas as etapas da navegação, permitindo-lhe retornar facilmente às páginas anteriores.

\subsection{Sistema de rotulagem}

Dentro dos sistemas de AI estão os sistemas de rotulagem, que objetivam transmitir a informação/conteúdo de forma eficiente e eficaz sem ocupar ou obstruir a página. Conforme Rosenfeld, Morville e Arango (2015), rotulagem é uma forma de representação, pois, assim como usamos palavras faladas para representar os conceitos e pensamentos, usamos rótulos para representar os maiores pedaços de informações em nossos ambientes de informação. Assim, classificam rótulos em dois tipos: textual e icônico. O textual se refere a uma apresentação do bloco de informações por meio de texto, e o icônico, em forma de imagem ou ícone.

Partindo desses pressupostos, pôdese verificar que o site aqui analisado contém os dois tipos de rotulagem, como também destina as informações para um público bem definido, há uma teia complexa de hiperlinks, mas há problemas com granularidade e au- sência de padronização das fontes tipográficas e dos elementos visuais.

Quanto à granularidade, há uma repetição de palavras que gera, em nossa análise, uma redundância excessiva e a demanda do redimensionamento do sistema de rotulagem. Também foram encontrados rótulos textuais formados por siglas. As siglas, embora consumam pouco espaço digital na tela, tendem a ser eficientes na comunicação apenas quando o usuário conhece a sigla. Em nosso enxergar, os rótulos compostos por siglas também devem ser objeto de modificação para o melhoramento da navegação no site da Secretaria Nacional de Política para as Mulheres.

O sistema de rotulagem apresenta problemas em suas diretrizes gerais na apresentação dos rótulos, na granularidade, na sintaxe e completude semântica. No entanto, sua audiência está bem definida nos rótulos analisados. Os rótulos usados na navegação social são adequados, feitos com paleta de cores padronizadas e levando usuários do site da Secretaria Nacional de Política para as Mulheres, adequadamente, para as redes sociais desta instância de governo.

\subsection{Sistema de busca}

Prosseguindo a análise com o sistema de busca e, tendo como pressuposto que seu objetivo é auxiliar na localização e no acesso rápido às informações armazenadas e apresentadas no site, apresenta como meca- 
nismo de busca por item conhecido, com recurso de linguagem natural e recurso de visualização por listagem. No campo de busca, não utiliza algoritmos de metabuscadores, mas utiliza o sistema de busca próprio do CMS plone. Nele, os usuários podem escolher a forma de apresentação dos resultados das pesquisas pelas seguintes ordenações: data, relevância ou ordem alfabética. Também é possível ordenar os resultados da busca pelo tipo do item, podendo ser: agen- da diária, áudio, página, evento, conteúdo externo, arquivo, imagem, link e notícia. Apresenta também em sua estrutura: links contextuais, títulos, opções do sistema de navegação e termos de indexação.

Com base na análise do site estudado, a partir dos pressupostos teóricos e sistêmicos da AI, perceber-se pontos relevantes que podem interferir no encontro, uso e disseminação da informação de forma favorável e desfavorável, sintetizados no Quadro 2.

Quadro 2 - Aspectos positivos e negativos do site

\begin{tabular}{|c|c|c|}
\hline $\begin{array}{l}\text { Sistemas de } \\
\text { Arquitetura da } \\
\text { Informação }\end{array}$ & Pontos Positivos & Pontos Negativos \\
\hline Organização & $\begin{array}{l}\text { - Organiza as publicações por ordem } \\
\text { cronológica, o que facilita a recuperação } \\
\text { das informações; } \\
\text { - No menu superior, principal, apresenta } \\
\text { um esquema por tópicos que sintetiza } \\
\text { bem as partes importantes e mais procu- } \\
\text { radas do site; } \\
\text { - Quanto aos hipertextos apresentados } \\
\text { no site, todos foram localizados e dimen- } \\
\text { sionados direto a sua finalidade. }\end{array}$ & $\begin{array}{l}\text { - Há uma quantidade demasiadamente exagerada } \\
\text { de tópicos na coluna vertical que pode confundir } \\
\text { o usuário e até mesmo desistir da busca, devido à } \\
\text { extensa possibilidade de acessos; } \\
\text { - Os vídeos não são organizados por categoria e } \\
\text { não apresentam datas dos eventos e de publicação. }\end{array}$ \\
\hline Navegação & $\begin{array}{l}\text { - Audiência bem definida; } \\
\text { - Há uma diversidade de conteúdos em } \\
\text { destaque com uso de imagens e textos; } \\
\text { - Atualizam constantemente as redes } \\
\text { sociais indicadas no site, além de possibi- } \\
\text { litarem o compartilhamento das publica- } \\
\text { ções nelas. }\end{array}$ & $\begin{array}{l}\text { - Repetição da expressão "ir para". } \\
\text { - Tópicos na navegação global, que poderiam ser } \\
\text { incluídos em categorias gerais, pois são muitas } \\
\text { páginas que se subdividem, causando uma polui- } \\
\text { ção visual no site; } \\
\text { - Utilização de siglas na navegação global. }\end{array}$ \\
\hline Rotulagem & $\begin{array}{l}\text { - O sistema de apresentação dos dois } \\
\text { tipos: textual e icônico; } \\
\text { - Há possibilidade de hiperlinks; } \\
\text { - Fazem uso de cores vivas e alegres. }\end{array}$ & $\begin{array}{l}\text { - Granularidade comprometida com a redundância } \\
\text { dos rótulos; } \\
\text { - Ausência de padronização na fonte dos títulos e } \\
\text { dos conteúdos da página; } \\
\text { - Desatualização de alguns itens; } \\
\text { - Repetição excessiva de termos nos tópicos de } \\
\text { menu. }\end{array}$ \\
\hline Busca & $\begin{array}{l}\text { - A busca pode ser realizada por "item } \\
\text { conhecido"; } \\
\text { - Possibilidade de uso da linguagem } \\
\text { natural; } \\
\text { - Recurso de visualização dos resultados } \\
\text { da pesquisa, que possibilita ser ordena- } \\
\text { dos por data, relevância ou alfabética. } \\
\text { Como também pode ser filtrado por tipo } \\
\text { de item. Há links contextuais e indexação } \\
\text { de termos. }\end{array}$ & $\begin{array}{l}\text { - Os resultados não precisos, recuperando exces- } \\
\text { siva quantidade de publicações que não correlaci- } \\
\text { onam diretamente ao objetivo da busca. Isso se } \\
\text { deve a problemas de indexação dos conteúdos, } \\
\text { que por fim não recuperam corretamente. }\end{array}$ \\
\hline $\begin{array}{l}\text { Tesauros, } \\
\text { vocabulários } \\
\text { controlados e } \\
\text { metadados }\end{array}$ & -- & $\begin{array}{l}\text { - Não há indícios da adoção e uso de tesauros ou } \\
\text { de vocabulários controlados no site, haja vista o } \\
\text { mecanismo de busca não recuperar por termos, } \\
\text { mas por repetição de palavras no texto. Sugere-se } \\
\text { o uso desses mecanismos para melhorar a navega- } \\
\text { ção e a recuperação da informação. }\end{array}$ \\
\hline
\end{tabular}

Fonte: Dados da pesquisa (2017). 
A análise dos resultados acima permitiu identificar aspectos positivos e negativos na estrutura arquitetural do site em estudo. A Netnografia possibilitou a compreensão da base sistêmica do site, interações nos recortes analisados nas atividades comunicacionais com os usuários, bem como uma melhor compreensão sobre os sistemas e elementos da AI demonstrados no Quadro 2.

\section{CONSIDERAÇÕES FINAIS}

O trabalho teve como intuito contribuir através da AI na estruturação das camadas de informações do site Secretaria Nacional de Políticas para Mulheres. Assim, houve discussões sobre a questão de gênero e a AI, a fim de entender melhor o objeto de estudo no ambiente digital, enquanto disseminador de informações para conscientização das mulheres quanto a seus direitos e lutas, e produtor de ações no combate à violência e discriminação contra mulher.

Dessa forma, foram utilizados amplamente os autores Rosenfeld, Morville e Arango (2015), na análise dos dados, por têlos como referências na AI, que possibilitaram averiguar os elementos que a compõem e os melhoramentos que devem ser observados e corrigidos para melhor interação dos usuários com o site e, consequentemente, poder agregar e proporcionar mais valor ao órgão, aumentando seu potencial de impacto na população, aproximando cada vez mais a informação ao usuário. Além disso, considera-se a Netnografia como estudo relevante para o entendimento das formas de interação dos usuários no ambiente virtual.

Com base nos aspectos teóricos dos referidos autores, os resultados obtidos na investigação possibilitaram listar alguns ajustes no site, conforme Quadro 2, como a necessidade de uma redefinição das taxonomias dos tópicos por haver problemas de repetição e uso de siglas, bem como na estrutura organizacional dos tópicos que possam direcionar e reduzir a quantidade de opções existentes na navegação global por termos mais gerais e claros. Além disso, há também problemas nos metadados e na recuperação das informações, que, apesar das várias opções de filtro e ordenamento, não possibilitam ao usuário obter a informação que necessita de forma rápida e precisa. Ademais, sugere-se melhorar a padronização das fontes tipográficas da página.

Ressalta-se a importância de haver novos estudos sobre as minorias e sobre os ambientes de informação digital relacionados a estas minorias, por contribuírem no combate às formas de preconceito, discriminação e violência, além de possibilitar novos olhares sobre os estudos de AI nestes ambientes digitais, que tem um foco atípico.

\title{
INFORMATION ARCHITECTURE IN THE GENDER CONTEXT: AN ANALYSIS OF THE SITE OF THE NATIONAL SECRETARIAT FOR WOMEN POLICY
}

\begin{abstract}
This research aims to analyze the Information Arcbitecture of the website of the National Secretariat of Politics for Women, in order to diagnose possible problems in the architectural structure of the site and suggest modifications in order to correct inconsistencies in the Information Architecture. The present research is bibliographical and exploratory based on the theoretical assumptions of Information Architecture in a social context linked to the debate on gender issues. Methodologically, it uses the Netnography as a way to collect data analysis. The analyzes point out, among other results, the need for adjustments in the architecture of the website of the National Secretariat for Politics for Women, in the standardization of the typographic fonts used in the page, and in the redefinition of topics in the navigation system to improve information retrieval through search system.
\end{abstract}

Keywords

Information architecture. Gender. National Secretariat for Politics for Women.

Artigo recebido em 18/08/2018 e aceito para publicação em 24/12/2018 


\section{REFERÊNCIAS}

ALBUQUERQUE, A. R. R.; LIMAMARQUES, M. Sobre os fundamentos da arquitetura da informação. Perspectivas em Gestão \& Conhecimento, v. 1, n. Especial, art. 5, p. 60-72, 2011. Disponível em: http://www.periodicos.ufpb.br/ojs/index.p $\mathrm{hp} / \mathrm{pgc} /$ article/view/10827/6075. Acesso em: 20 dez. 2018.

ALMEIDA, J. P. As multifaces do patriarcado: uma análise das relações de gênero nas famílias homoafetiva. 2010. 116f. Dissertação (Mestrado em Serviço Social) - Universidade Federal do Pernambuco, Recife, 2010.

AMARAL, A.; NATAL, G.; VIANA, L. Netnografia como aporte metodológico da pesquisa em comunicação digital. Famecos/PUCRS, Porto Alegre, n. 20, p. 34-40, 2008.

BENTES PINTO, V.; RODRIGUES TABOSA, H.; VIDOTTI, S. A. Arquitetura da informação: uma teologia para a representação da informação de prontuário eletrônico do paciente $I n$ : ENCONTRO NACIONAL DE PESQUISA EM CIÊNCIA DA INFORMAÇÃO. 12., 2011, Brasília. Anais.... Brasília: UNB/ANCIB, 2011. v. 1. p. 1-18.

BRASIL. Ministério da Justiça e Cidadania. Secretaria Nacional de Políticas para as $\mathrm{Mu}-$ lheres. 2017. Disponível em:

http://www.spm.gov.br/. Acesso em: 21 ago. 2017.

CARDOSO, G. Os Media na sociedade em rede. Lisboa: Serviço de Educação e Bolsas; Fundação Calouste Gulbenkian, 2006

CARVALHO, M. P. O conceito de gênero: uma leitura com base nos trabalhos do GT Sociologia da Educação da ANPEd. Revista brasileira de Educação, v. 16, n. 46, p. 99 266, jan./abr. 2011. Disponível em: http://www.scielo.br/pdf/rbedu/v16n46/v 16n46a06.pdf. Acesso em: 20 dez. 2018.

CORRÊA, M. V.; ROZADOS, H. B. F. A netnografia como método de pesquisa em Ciência da Informação. Encontros Bibli: revista eletrônica de Biblioteconomia e Ciência da Informação, Florianópolis, v. 22, n. 49, 2017. p. 1-18. Disponível em:

https://periodicos.ufsc.br/index.php/eb/art icle/view/1518-2924.2017v22n49p1/34047. Acesso em: 20 dez. 2018.

JESUS, J. G. Orientações sobre identidade de gênero: conceitos e termos. Brasília: Publicação online, abr. 2012. Disponível em: http://www.diversidadesexual.com.br/wpcontent/uploads/2013/04/GÊENERO-

CONCEITOS-E-TERMOS.pdf. Acesso em: 20 dez. 2018.

MINAYO, M. C. S. O desafio do conhecimento. São Paulo: Hucitec, 1982.

OLIVEIRA, H. P. C.; VIDOTTI, S. A. B. G. Arquitetura da informação digital: conexões interdisciplinares dentro da abordagem sistêmica. In: CAVALCANTE, L. E.; BENTES PINTO, V.; VIDOTTI, S. A. B. G. Ciência da informação e contemporaneidade: tessituras e olhares. Fortaleza: Edições UFC, 2012. p. 184-202.

OLIVEIRA, H. P. C.; VIDOTTI, S. A. B. G.; BENTES PINTO, V. Arquitetura da informação pervasiva [recurso eletrônico] São Paulo: Cultura Acadêmica, 2015.

ROSENFELD, L.; MORVILLE, P.; ARANGO, J. Information architecture for the Web and Beyond. 4th ed. Canadá: O’Reilly, 2015.

SAFFIOTI, H. I. B. Gênero, patriarcado, violência. São Paulo: Editora Fundação Perseu Abramo, 2004.

SANTOS, R. L. G. Usabilidade de interfaces e arquitetura de informação: alguns aspectos da organização de conteúdo para o meio 
digital. In: CONGRESSO DA BRASILEI-

RO DE ERGONOMIA, 11., 2001, Grama-

do. Anais... Gramado: Abergo, Associação

Brasileira de Ergonomia, 2001.

SILVA, P. M.; DIAS, G. A. A arquitetura da informação centrada no usuário: estudo do website da biblioteca virtual em saúde (bvs). Encontros Bibli: revista Eletrônica de Biblioteconomia e Ciência da Informação, Florianópolis, n. 26, 2o sem. 2008. Disponível em:

https://periodicos.ufsc.br/index.php/eb/art
icle/viewFile/7200/6647. Acesso em: 23 ago. 2017.

TELES, M. A. A. Breve histórico do feminismo no Brasil. São Paulo: Brasiliense, 1999.

TORRÃO FILHO, A. Uma questão de gênero: onde o masculino e o feminino se cruzam. Cadernos pagu, Campinas, n.24, p.127-152, jan/jun, 2005. Disponível em: http://www.scielo.br/pdf/cpa/n24/n24a07. pdf. Acesso em: 23 ago. 2017. 